\title{
Instilling Teamwork Spirit and Industry Internship into Computer Engineering Education for Chinese Situation
}

\author{
HUANG Jun ${ }^{a}$, HAN Lingli ${ }^{\text {b }}$ \\ Department of Computer Science and Technology, China Jiliang University, Hangzhou, 310018, \\ China \\ aemail: hjun@cjlu.edu.cn, bemail: hanlli@cjlu.edu.cn
}

\begin{abstract}
Keywords: Engineering Education; Project-based Learning; Industry Internship Program; Excellent Engineers Training Program
\end{abstract}

\begin{abstract}
Current education mode of the computer science departments in China universities is more and more incompatible with the industry demand. To effectively solve this problem, it would be necessary, on one hand, to change the learning methodology to improve undergraduate engineering knowledge and ability. On the other hand, the gap should be filled between universities current education mode and industry demands for engineers. The paper presented the Computer Excellent Engineers Training Program, analyzed the effect of the program implemented in computer engineering education of the department of Computer Science and Technology at China Jiliang University.
\end{abstract}

\section{Introduction}

Traditional computer science training model in higher education of China, pay much attention to theoretical contempt for practice, emphasis on individual academic ability while ignoring the spirit of engineering [1]. People attach importance to knowledge learning underestimate innovation training, resulting in less engineering ability to apply computer science graduates, the overall quality is not high, professionalism is not sufficient to meet the social, the actual needs. McKinsey Global Institute said "China's educational system is biased theory, almost no Chinese students by the actual project and team work training, and European and North American students in teams to solve practical problems" [2]. That has led to a situation where the traditional computer science education in China is heavily out of synch with reality.

To effectively solve this problem, it would be necessary, on one hand, to change the learning methodology to guarantee the educational program can provide the engineering abilities for the students and enabling future professionals to correctly tackle the problems that students will face during their professional career. On the other hand, we should fill the existing gap between software education and industry demands for software engineers, which lead to a lack of motivation amongst students with existing industrial experience. In this paper, we first describe how to adapt project-based learning method to promote students teamwork abilities in computer science education within the department of Computer Science and Technology (CST) at China Jiliang University. Then our industry internship program is introduced to ensure students smooth transition from course study to industry practice and experience. The aim of the new methods and program was to promote the students' engineering abilities and meet the demands of future successful software engineer.

\section{Project-based Learning to Improve Teamwork Abilities}

Teamwork is the actions of individuals, brought together for a common purpose or goal, which subordinate the needs of the individual to the needs of the group [3]. In traditional education, the undergraduate students of computer often work alone, write for the teacher alone, and rarely make presentations and seldom receive any specific training on how to function collaboratively. To address these problems and create an environment where undergraduates can be systematically 
exposed to the teamwork process and given opportunities to become involved with different group, the CST have put forward a model in the program for undergraduate computer courses. By adapting project-based learning methodology, the students can be guided to work on long-term challenges that involve project problems. This helps students see the complexity and interdisciplinary aspects of any job or activity in a more realistic fashion, helping them prepare more effectively for the real challenges ahead.

The first step of the model is to present a one-semester introduction to computer science as a selective course to first- year students. The course is intended as a broad introduction to computer science research for students who wish to know research knowledge in computing and presented particular emphasis on computer project problem solving. Project problems are selected from a variety of interesting areas, which can enable students to become well rounded in these areas, have proper background and knowledge to carry out interesting project. In addition, in introduction to computer science, an emphasis is also on the knowledge about design of algorithms and implementation of those algorithms using the computer programming language. The outstanding students are required to finish assignments which include writing programs to recognize sentence boundary, identifying each word and writing simple pattern matching. Our experience is that if a student lacks serious programming skills, then that deficiency is difficult to make up, and hard to participate the computer project .

The second is to let students choose the project topics and select their own teams based upon one another's computer science background and the type of project each student wanted to develop at their second-year. Selection of project topics is a key step to produce student creativity and innovation. In the chose of topics, we first should make sure that the topic is placed within the student's field of interest. In addition, goal of topic is presented with little definition, giving much place to many ideas on possible solutions. To motivate students to start their projects, the teacher presented videos and photos of devices related to the topic. The teacher also analyzed model of the project key problems with the students. In addition, the teachers will help students recognize and make the most of their own and one another's preferred roles, outline with them a list of team roles, have them determine which role(s) suits them best, and give them time to discuss within their groups how their particular roles will complement those of other group members.

The third is to start the project action in team. At this step, the team members are required to agree on what needs to be done and by whom. Each student then determines what he or she needs to do and takes responsibility to complete the tasks. They can be held accountable for their tasks, and they hold others accountable for theirs. It was clearly established that carrying out the project would be "a required condition to pass the course" and that just a design and report wouldn't be accepted. The project had to be filish. Later, each team group got to shape and define their own ideas of solution influenced by their interests, their capabilities and their analysis of the problem. In order to follow up and support to the teams, the professor met with the teams frequently, mainly to be informed about the individual and group performance, to promote reflexive thinking about their actions and decisions, and to analyze the technical and operational aspects of their ideas.

At the end of the project work, the students handed in a final report, included the portfolio of evidences and make self and peer evaluation and made public presentations of their projects to the entire class and their teachers. The teacher evaluated the project teams' learning achievements according team project work and individual contribution to the teamwork through interviews, surveys and focus groups meetings.

\section{Industry Internship Program to Fill Gap between University and Industry}

Beyond the reform of the learning methodology to improve the student teamwork abilities mentioned above, we also launched a student industry internship programs to fill the existing gap between our computer engineering education and industry demands for students. The industry internship program is an integral part of our computer excellence engineer plan. As part of the class students were required to sign a statement of goals with the IT companies of choice outlining their desired objectives for the 12-week experience. At beginning of the first three weeks of internship, 
each student need to develop a project topic proposal, which layouts the project topic, work involved, and related technologies will be used, etc. During the internship, students kept a daily diary documenting activities and key benchmarks of their goals. Upon returning to campus in the fall they completed a real project and delivered an oral presentation summarizing the experience. Since 2010, 95\% of graduates participated in the internship experience and over half enrolled in the credit option. During the internship students gain not only practical "hands-on" experience of the application of computing and software engineering skills but also ability to learn and adapt -'learn how to learn'.

In order to ensure the smooth transition from course study to industry practice, we first launched a pilot course that increased student responsibilities during their internship program. In students choosing advisers, we encourage each student choose two advisers, one from university, and one from the company. Company adviser could supervise student with the project development, and university adviser could guide student with student dissertation work, which not only fills the knowledge gaps between university and industry but also builds a communication bridge between universities and enterprises. In addition the department has collaborated with many local software enterprises to build similar industrial environment on campus, which became on-campus practice base. The on-campus practices base bring real industrial project into campus to enhance the students' capability on software development. Joint laboratories is another form of on-campus collaboration with industrial companies, which mainly used for teaching mission and software development, equipped with developing platform and software kits provided by software companies. The enterprises will periodically offer technical lectures and guidance to staffs and students in the school. The establishment of the joint labs also helps us to form a reasonable lecture system and industrial teaching and managing methods, and to achieve the goal of cultivation of computer engineering talents.

The another major problems is that most teachers of our university lack recent industrial experience or direct contact to industry, and as such are not aware of the modern software engineering practices. These issues have led to a situation where our education is heavily out of synch with reality. As teachers have not used them, they are not truly capable of conveying methodologies in teaching as these methodologies can only be learned through practicing them [4]. Therefore faculty internships in our program are also an extremely important aspect in improving a faculty member's ability to relate current and industrially relevant technical information to their students, and potentially the industry's future employees. Our program consisted of three days per week for nine weeks, covering various aspects of software engineering technical operation. The period was broken down into three segments: software developing, software testing and engineering project planning. Each of the sections provided an opportunity to observe, and participate to a limited degree, in the various aspects of their IT business, either directly or indirectly incorporated into the classroom. We also encourage our teachers to teach at the same time, participate in the industry's production practices and scientific research activities, participate in the development of new products, new technologies, new methods, exploitation and dissemination, keep close contact with industry contacts, go deep into business, industry and enterprise development, know industry developments and future directions.

In addition, we encourage teachers to start their own IT small businesses and provide them additional conditions, such as the concentration of venues, facilities, help obtaining administrative permits. Teachers in the process of operating their own businesses will constantly improve their professional and technical capacity and technical ability. At the same time, we actively employ those have abundant computer professional technicians and management personnel from famous IT enterprises as part-time teacher and hire professional and technical personnel to teach or teach to the school on a regular basis. They pass or advanced professional knowledge of enterprise and technology and make the students can accept the industrial experience education with their own work practice and development projects 


\section{Result Analysis}

The China Jiliang University began the Computer Excellent Engineers Training Program experiment in 2010. The continuous assessment of students, the surveys carried out as well as the results obtained let us analyze the experience. We were able to check the usefulness of the implementation of our program to meet demand of Excellent Engineers Training Program. Some of the aspects valuated were: 1) Engineering experience development, 2) Development of the generic/specific competences in computer engineering filed, 3) Assessment of the teaching method.

As regards abilities and skills developed by the students, the results obtained coming from the last experience showed that the abilities and skills more developed were: self learning, knowledge integration, oral and written communication, critical capacity, team work and initiative. The results obtained let us confirm the usefulness of program on computer engineering abilities.

Concerning the usefulness of the experience from the point of view of the program, students express the need of a greater effort (97\%), compared to traditional methods. However, they have also recognized that they have learned more (77\%). They also valued its usefulness as an approximation to the real world (90\%). In $60 \%$ of cases the students recommended this method of learning. They also underlined some difficulties founded. Above all, they claimed lack of time, a greater help from lecturer and increasing load of work.

In addition, with the great improvement of awareness of student's innovation abilities and engineering skills, our graduates were warmly welcomed by the employers. In 2011, the employment rate of our graduates raises the 10 percentage points and student employability confidence also has increased greatly. A manager of one software development company made the evaluation on our graduates. "A lot of work of my company is project-based, where every staff is required to work with four to 10 different people staffed on a project. It is critical that one can handle amount of engineering work as well as be able to interact with all members of the team. The CST education prepared their graduates engineering experience and gave them teamwork skill for how to deal with group dynamics”.

\section{Conclusion}

The paper has presented our Computer Excellent Engineers Training Program, analyzed the effect of the program implementation in computer engineering education of the department of Computer Science and Technology at China Jiliang University. In the educational process of this new program, on the one hand, the importance of the teacher should be confirmed since the new times demand a new role for teachers. The successful implementation of the methodologies involves changes to a significant portion of the teaching process, from instructional design and organization to development of learning materials, and even teacher activity inside the classroom. Another success factors is enterprise, which can provide our students industrial experience, up-to-date industrial best practices and tools.

\section{References}

[1] Yunhe Pan, Seize the Opportunity to Vigorously Cultivating Innovative Engineers, China Higher Education, Vol 24,pp.4-6, December.2009. (In Chinese)

[2] HUANG Jun, CHEN Guang-ping, Improving Undergraduates' Engineering Abilities With Chinese Situation. Computer Science \& Education (ICCSE), 2012 7th International Conference. pp. 1508-1511.

[3] CHEN Xiang, QIU Ye. Experiment Teaching Reform for Software Engineering Majors Based On CDIO, Proceedings of the 2nd International Conference On Systems Engineering and Modeling (ICSEM-13),2013, pp.1046-1049.

[4] Matti Luukkainen, Arto Vihavainen, Thomas Vikberg. Three Years of Design-based Research to Reform a Software Engineering Curriculum. SIGITE'12, October 11-13, 2012, Calgary, Alberta, Canada. pp.209-214. 